\title{
Serial blood pressure measurements
}

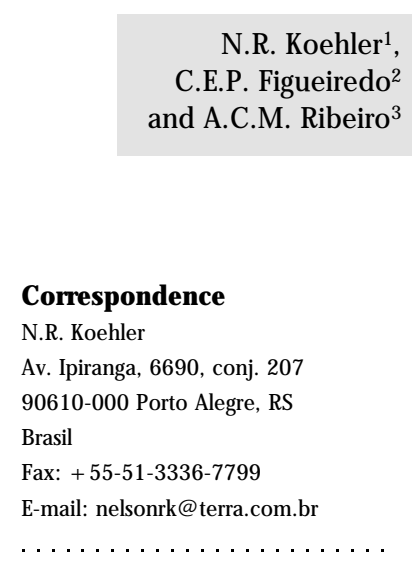

Received July 19, 2001 Accepted February 14, 2002

Abstract

The objective of the present investigation was to study the effects of a 60 -s interval of venous congestion between two noninvasive measurements of arterial blood pressure (ABP) on the fluctuation of ABP, assessed by the standard deviation of the differences between two readings. ABP was measured in 345 successive patients, at rest, four times each. For 269 participants, one pair of readings was obtained with a 60-s interval and the other pair without an interval. For 76 patients, the first pair was read at the same interval, and the second pair had venous congestion interposed and there was no waiting interval. There was no increased ABP oscillation, either when there was no interval between ABP readings, or when venous congestion was interposed compared to pairs of ABP measurements performed with a 60 -s interval. There was no increase in ABP oscillations when successive $A B P$ readings were taken without an interval or even with venous congestion interposed. Contrary to the present belief, there seems to be no loss of reliability when blood pressure recordings are taken immediately one after another, in the clinical setting.

\section{Introduction}

Hypertension is a leading risk factor for coronary artery disease, congestive heart failure, renal disease and stroke. Cost, invasiveness and technical limitations restrict the use of the most accurate devices available for measuring arterial blood pressure (ABP). Therefore, ABP cuff measurement remains the most appropriate screening test for hypertension. This method of ABP measurement is prone to errors resulting from instrument, observer and patient factors. Among other standards, guidelines on ABP measurement recommend that two or more readings separated by at least $30-60 \mathrm{~s}$ should be averaged. The recommendation of having an interval of 30 to $60 \mathrm{~s}$ between two consecutive ABP measurements is present in textbooks and even in the guidelines prepared by societies or committees involved in blood
Key words

- Blood pressure

- Arterial blood pressure oscillations

- Venous congestion

- Arterial blood pressure measurement technique

- Arterial blood pressure fluctuations in the short term pressure and high blood pressure investigation (1-8). However, we are not aware of documentation in the literature describing experimental studies supporting this recommendation.

There are reports that venous congestion following the first ABP measurement could be responsible for a possible alteration of the next reading (9). Foot blood flow is reduced under venous occlusion when the leg is positioned below the level of the heart. The increased response of precapillary resistance (by a local myogenic or sympathetic reflex) can act as a protective mechanism against edema formation (10). Although the existence of a peripheral circulation regulatory reflex in humans (the venoarterial cutaneous vasoconstrictor reflex) is known, an effect of venous congestion on $\mathrm{ABP}$ measurement is speculative.

When venous congestion is produced, 
hydrostatic overload develops, triggering the venoarterial cutaneous vasoconstrictor reflex, a physiological reaction that produces a reduction in local flow of about $50 \%$ through an increase in vascular resistance caused by vasoconstriction. This reflex consists of constriction of small arteries or arterioles in response to venous distension, probably corresponding to a local axonal reflex situated between a distension vein receptor and a constrictor arterial effector. Sympathetic alterations can affect the performance of this reflex (10).

Therefore, we decided to compare the oscillation of $\mathrm{ABP}$ assessed in pairs of measurements separated by the conventional 60 $\mathrm{s}$ interval with the variation observed without this delay between records. We also investigated the effect of venous congestion upon the second reading by comparing two measurements following the recommended time interval with pairs of readings with venous congestion interposed without an additional time interval.

\section{Patients and Methods}

A total of 345 consecutive patients had their ABP measured four times at rest, in the right arm, by the conventional noninvasive method. In group A $(\mathrm{N}=92)$, aged 21-86 years, blood pressure was measured in the sitting position using a mercury sphygmomanometer. In group B $(\mathrm{N}=158)$, aged 1780 years, blood pressure was measured with the patients in the supine position using a mercury sphygmomanometer. In group $\mathrm{C}(\mathrm{N}$ $=19$ ), aged 27-82 years, blood pressure was measured in the sitting position using an automatic Datascope device, model 2NEL (Datascope Corporation, Paramus, NJ, USA). In group $\mathrm{D}(\mathrm{N}=44)$, aged 17-82 years, blood pressure was measured in the supine position using a mercury sphygmomanometer. In group $\mathrm{E}(\mathrm{N}=32)$, aged $18-75$ years, blood pressure was measured using a Nihum Seimitsu Sokk (Nissei, Japan) digital elec- tronic device, model DS-91, with the subjects in the supine position.

All measurements were made by the first author. The first pair of readings was obtained at the beginning of the consultation, and the second one at the end. In groups A and $\mathrm{B}$ this sequence was inverted in one third of the subjects. The patients did not smoke or drink coffee during the last $15 \mathrm{~min}$. They were relaxed, the arm examined was at heart level and they did not cross their legs or talk during the examination. There was no randomization of the patients at admission to the study.

In the last two groups (D and E), the first pair of readings was obtained with an interval of $60 \mathrm{~s}$, while in the second pair of readings venous congestion of the right arm was caused immediately after the first reading, with no delay before the second reading.

The patients attended either the private clinic of one of the authors (groups B, C, D and $\mathrm{E}$ ) or a cardiology outpatient clinic of the public health system (Sistema Unificado de Saúde, SUS). Systolic blood pressure was measured at Korotkoff phase I and diastolic blood pressure at Korotkoff phase V.

The noninvasive automatic and non-automatic blood pressure devices used were not checked for previous validation because the variable under study was blood pressure fluctuation or oscillation and not the accuracy of measurements. Both mercury sphygmomanometers used had meniscus at zero level, column in vertical position and were free of dust and air bubbles.

Venous congestion was obtained by using the same cuff as used for blood pressure measurements. The pressure exerted was the mean of the systolic and diastolic pressures over a period of 10 to $15 \mathrm{~s}$, causing venous dilatation and cyanosis of the right upper limb.

Patients with hemodynamic instability, cardiac arrhythmias, pregnant women, patients with weak Korotkoff sounds and patients younger than 15 years were not included in the study. 
Short-term variation in the arterial pressure at rest (seconds to minutes) was reported as the mean of the standard deviations of the differences in arterial pressure between the pairs of measurement separated by a 60 -s interval or by no interval or with venous congestion interposed.

The paired $t$-test was used to compare the fluctuation between paired samples, with the level of significance set at $\mathrm{P}<0.05$.

\section{Results}

The clinical and demographic characterization of the patients are displayed in Table 1. As observed in Table 2, in groups B, C, D and $\mathrm{E}$ the fluctuation of $\mathrm{ABP}$ in the pairs of measurement without an interval or with venous congestion interposed was not significantly greater than that observed in the ABP measurement pairs with a 60 -s interval

Table 1. Clinical and demographic characterization of the patients.

\begin{tabular}{lcccccccc} 
Groups & N & $\begin{array}{c}\text { Age (mean } \pm \text { SD) } \\
\text { Range (min-max) }\end{array}$ & Men & Women & White & Non-white & Normotensive & Hypertensive \\
\hline A & 92 & $\begin{array}{c}57 \pm 12 \\
21-86\end{array}$ & 16 & 76 & 71 & 21 & 23 & 69 \\
B & 158 & $\begin{array}{c}47 \pm 16 \\
17-80\end{array}$ & 65 & 93 & 138 & 20 & 83 & 75 \\
C & 19 & $\begin{array}{c}56 \pm 16 \\
27-82\end{array}$ & 5 & 14 & 18 & 1 & 11 & 8 \\
D & 44 & $\begin{array}{c}49 \pm 18 \\
17-82\end{array}$ & 18 & 36 & 37 & 7 & 28 & 16 \\
E & 32 & $57 \pm 13$ & 9 & 23 & 22 & 10 & 5 & 27 \\
Total & 345 & $53 \pm 14$ & 113 & 232 & 286 & 59 & 150 &
\end{tabular}

Table 2. Analysis of the difference in mean fluctuation between two pairs of blood pressure measurements (systolic and diastolic) with and without a 60-s interval between them.

\begin{tabular}{lcccccc}
\hline Group & $\mathrm{N}$ & Interval (s) & Systolic variation & $P$ & Diastolic $(\mathrm{mmHg})$ & $P$ \\
\hline A & 92 & 60 & $5.47 \pm 0.53$ & $0.019^{*}$ & $3.41 \pm 0.29$ & 0.249 \\
& & 0 & $4.14 \pm 0.41$ & & $2.94 \pm 0.29$ & \\
B & 158 & 60 & $3.60 \pm 0.27$ & 0.141 & $2.91 \pm 0.23$ & 0.054 \\
& & 0 & $3.11 \pm 0.24$ & & $2.26 \pm 0.17$ & \\
C & 19 & 60 & $3.46 \pm 0.69$ & 0.080 & $2.20 \pm 0.46$ & 0.304 \\
& & 0 & $5.32 \pm 0.73$ & & $3.24 \pm 0.66$ & \\
D & 44 & 60 & $3.25 \pm 0.41$ & 0.462 & $2.69 \pm 0.33$ & 0.687 \\
& & $0+\mathrm{VC}$ & $2.80 \pm 0.41$ & & $2.96 \pm 0.32$ & \\
E & 32 & 60 & $5.70 \pm 1.11$ & 0.090 & $5.75 \pm 1.14$ & 0.611 \\
& & $0+\mathrm{VC}$ & $8.29 \pm 1.22$ & & $6.45 \pm 0.97$ &
\end{tabular}

The other comparison was among mean changes in pairs of blood pressure measurements with a 60-s interval versus no interval and venous congestion interposed. Variation is reported as the mean of standard deviation $(\mathrm{mmHg}) \pm$ mean error. The readings were obtained from the right arm. VC: venous congestion interposed.

$* \mathrm{P}<0.05$ comparing groups with and without interval (bilateral t-test for paired samples). 
and no venous congestion between assessments. For group A the fluctuation in systolic ABP was significant and was greater for pairs of measurement obtained with a 60s interval. Analysis of smaller strata in groups $\mathrm{A}$ and $\mathrm{B}$ (women $v s$ men, white $v s$ nonwhite, adults $v s$ aged) did show significant differences in the oscillation of ABP with a 60 -s interval $v s$ no interval, with the variation being greater in $\mathrm{ABP}$ measurement pairs with a 60-s interval than in ABP pairs measured without such interval (data not shown).

\section{Discussion}

The data did not demonstrate a significantly greater variation in $\mathrm{ABP}$ between pairs of measurement without an interval and with interposed venous congestion when compared with the oscillation in pairs of measurement with a 60-s interval. Only one sample stratum (A) showed a significantly greater oscillation in systolic ABP in the pairs of measurements with a 60-s interval.

The present results do not support the established guidelines for blood pressure measurement techniques. Neither elimination of a time interval nor the occurrence of venous congestion between measurements increased $\mathrm{ABP}$ variation in the sample studied. The absence of randomization of the subjects upon admission to the study was a real limitation of the present study.

There is evidence of a strong correlation between venous and arterial blood flow at least under certain conditions. The skin circulation not only provides the skin with nutrients, but is also an important factor in thermoregulation: in the presence of thermal changes, human beings regulate the tonus of skin vessels through many reflexes which modulate the heat exchanges with the environment. Extremities such as the plantar ar- eas of toes, palmar areas of finger extremities, nose and ears present a plethora of arterial-venous anastomoses with a rich innervation, as well as nutrient capillary loops, venous plexuses and subpapillary arteries (8). The human subcutaneous blood flow is reduced by approximately $50 \%$ when the transmural vascular pressure rises by 25 $\mathrm{mmHg}$ or more. This phenomenon also occurs in the skin and skeletal muscle. Precapillary resistance increases while postcapillary resistance is reduced during venous stasis (9).

With venous congestion in the extremities, a reflex response of probably peripheral origin occurs, causing arterial constriction and blood flow reduction to these tissues (10). This phenomenon was investigated in cirrhotic patients with or without palmar erythema and compared with controls (11). In the control subjects blood flow reductions were observed after venous occlusion, with a rise in vascular resistance. However, arterial pressure in the corresponding area was not estimated. In cirrhotic patients with palmar erythema, the venoarterial cutaneous vasoconstrictor reflex was not affected in the dorsum of the hand, but was depressed in the palmar region. Nevertheless, the authors did not report that venous congestion affected ABP.

Our main finding was that overall results do not support the hypothesis that absence of the time interval or presence of venous congestion that may occur in clinical practice significantly affects the ABP oscillation that occurs naturally.

\section{Acknowledgements}

The authors are indebted to Drs. Mario Rigatto (in memoriam), Robert Clarke (Oxford) and Jandira Fachel. 


\section{References}

1. Kaplan NM (1997). Systemic hypertension: mechanisms and diagnosis. Definitions, prevalence, and consequences of hypertension. In: Braunwald E (Editor), Heart Disease: A Textbook of Cardiovascular Medicine. 5th edn. W.B. Saunders, Philadelphia, PA, USA, 819.

2. Oparil S (2000). Arterial hypertension. In: Goldman L \& Bennett J C (Editors), Cecil Textbook of Medicine. 21st edn. W.B. Saunders, Philadelphia, PA, USA, 258273.

3. Rourke RA, Shaver J Á, Salemi R, Silverman ME \& Schlant RC (1998). The history, physical examination and cardiac auscultation: methods for measuring the arterial pressure. In: Alexander RW, Schlant RC, Fuster V, Rourke RA, Roberts R \& Sonnenblick EH (Editors), Hurst: The Heart, Arteries and Veins. 9th edn. McGraw-Hill, New York, NY, USA, 254258.

4. Feldman RD, Campbell NR \& Larochelle P
(1999). Clinical problem solving based on the 1999 Canadian recommendations for the management of hypertension. Canadian Medical Association J ournal, 161 (Suppl 12): S18-S22.

5. Feldman RD, Campbell N, Larochelle $P$, Bolli P, Burgess ED, Carruthers SG, Floras J S, Haynes RB, Honos G, Leenen FHH, Leiter LA, Logan AG, Myers MG, Spence J D \& Zarnke KB (1999). Canadian recommendations for the management of hypertension. Task Force for the Development of the 1999 Canadian Recommendations for the Management of Hypertension. Canadian Medical Association J ournal, 161 (Suppl 12): S1-S17.

6. American Society of Hypertension (1992). Recommendations for routine blood pressure measurement by indirect cuff sphygmomanometry. American J ournal of Hypertension, 5: 207-209.

7. Consenso Brasileiro para o Tratamento da Hipertensão Arterial (1998). III Consenso
Brasileiro para o Tratamento da Hipertensão Arterial. Sociedade Brasileira de Hipertensão, Campos do J ordão, SP, Brazil.

8. J oint National Committee on Prevention, Detection, Evaluation, and Treatment of High Blood Pressure (1998). The sixth report. Archives of Internal Medicine, 157: 2413-2446.

9. Hassan AA, Rayman G \& Tooke J E (1986). Effect of indirect heating on the postural control of skin blood flow in the human foot. Clinical Science, 70: 577-582.

10. Henriksen O (1976). Effect of chronic sympathetic denervation upon local regulation of blood flow in human subcutaneous tissue. Acta Physiologica Scandinavica, 97: 377-384.

11. Leonardo G, Arpaia MR, Del Guercio R \& Coltorti M (1992). Local deterioration of the cutaneous venoarterial reflex of the hand in cirrhosis. Scandinavian J ournal of Gastroenterology, 27: 326-332. 